Bulletin d'Histoire Contemporaine de l'Espagne

$54 \mid 2020$

Les espaces du politique dans l'Espagne du Trienio liberal (1820-1823)

\title{
El Servicio Exterior de Falange y la diplomacia franquista después de 1945. Bases para una investigación
}

Le Service extérieur de la Phalange et la diplomatie franquiste après 1945. Bases pour une recherche

The Falange Foreign Service and Francoist diplomacy after 1945. Bases for an investigation

Iván Garnelo Morán

\section{(2) OpenEdition}

\section{Journals}

Edición electrónica

URL: http://journals.openedition.org/bhce/2783

DOI: 10.4000/bhce.2783

ISSN: 1968-3723

Editor

Presses Universitaires de Provence

Edición impresa

Fecha de publicación: 1 enero 2020

ISSN: 0987-4135

Referencia electrónica

Iván Garnelo Morán, « El Servicio Exterior de Falange y la diplomacia franquista después de 1945. Bases para una investigación », Bulletin d'Histoire Contemporaine de l'Espagne [En línea], 54 | 2020, Publicado el 01 julio 2020, consultado el 31 diciembre 2020. URL : http://journals.openedition.org/ bhce/2783; DOI : https://doi.org/10.4000/bhce.2783

Este documento fue generado automáticamente el 31 diciembre 2020.

Bulletin d'histoire contemporaine de l'Espagne 


\title{
El Servicio Exterior de Falange y la diplomacia franquista después de 1945. Bases para una investigación
}

\author{
Le Service extérieur de la Phalange et la diplomatie franquiste après 1945. Bases \\ pour une recherche
}

The Falange Foreign Service and Francoist diplomacy after 1945. Bases for an investigation

Iván Garnelo Morán

1 El Servicio Exterior de Falange ha sido una de las secciones de Falange Española menos estudiada por los investigadores. Desde la obra de H. R. Southworth ${ }^{1}$ en 1967, dónde por primera vez se habla de la Falange Exterior, a las aportaciones más recientes de Eduardo González Calleja ${ }^{2}$, y pasando por los trabajos de Florentino Rodao ${ }^{3}$, Francisco Veiga $^{4}$ o Antonio C. Moreno Cantano ${ }^{5}$, se han cubierto muchos aspectos de esa organización, como un todo o en sus actividades en países concretos, así como en su despliegue de propaganda política.

2 Aun así, estos trabajos no han conseguido ofrecer un estudio completo y sistemático del servicio falangista; sin embargo, la actividad de Falange Exterior puede ser un buen punto de partida para comprender cómo se fue construyendo parte de la diplomacia franquista tras la guerra mundial, y cómo ayudó a apuntalar la supervivencia del régimen tras el final del fascismo en Europa. En este sentido, este artículo forma parte de un trabajo e investigación más amplios que pretenden dar respuesta a la incógnita de por qué Franco y el régimen pudieron mantenerse en un mundo postfascista. Esta respuesta debe complementar la explicación clásica acerca de esta cuestión, que ha centrado el foco en una política exterior teledirigida al alineamiento con los Estados Unidos y el Bloque Occidental.

Por ahora, se ve plausible la opción de reconstruir una serie de biografías de algunos miembros del personal falangista del servicio que acabasen en el cuerpo diplomático, como es el caso de algunos personajes que se mencionan más adelante en el presente 
artículo. Pero, aun con esto, también parece necesario analizar qué fue y en qué consistió el Servicio Exterior de Falange Española, cuyo nacimiento es datado antes del inicio de la Guerra Civil Española, concretamente el 1 de enero de 1936 en Milán ${ }^{6}$, con el nombre de Sede de la Falange Exterior ${ }^{7}$. Aunque hablar del organismo como un cuerpo reglamentado e importante del partido antes del decreto del 20 de abril de $1937^{8}$ no sería del todo correcto. En mayo de 1935, José Antonio Primo de Rivera se encontraba en Italia para poder entrevistarse con Benito Mussolini - cosa que nunca llegó a suceder - y en esa visita se ultimaron los detalles para la formación de un núcleo falangista en el norte de Italia. Entre junio y diciembre se inició una ayuda de cincuenta mil liras por parte del principal dirigente falangista con el objetivo de formar dicho grupo ${ }^{9}$, lo que, a fin de cuentas, sería el inicio del ya mencionado Servicio Exterior de Falange Española.

4 Antes del 18 de julio de 1936 no hay información sobre núcleos organizados y coordinados desde la Falange en España, aunque es posible que grupos diseminados y desorganizados de simpatizantes fuesen reuniéndose en diferentes países. Será con el estallido de la Guerra Civil cuando se pueda empezar a constatar la formación de dichos grupos en el seno de colonias de españoles ${ }^{10}$ en el extranjero y con coordinación, todavía precaria, desde Falange Española - el partido previo a la unificación -. Esto puede observarse en la llegada, desde septiembre de 1936, de víveres, medicinas y ropa desde Latinoamérica, cuya recogida y repartición se haría a través del que sería el máximo dirigente falangista tras la muerte de Primo de Rivera, Manuel Hedilla ${ }^{11}$. Otro dato que nos da una pista sobra los núcleos a partir del 36 es el aumento de afiliados y simpatizantes que registra la organización fascista en esas fechas ${ }^{12}$.

5 Se observa, pues, que del mismo modo que quedó dividida la sociedad peninsular entre partidarios y detractores de los sublevados, la situación parecía repetirse entre los españoles en el extranjero, donde se empiezan a suceder muestras de apoyo a la República y al bando autoproclamado Nacional.

6 A partir del 6 de octubre de 1936 se iniciará desde España un impulso de las Falanges del exterior, pero hasta la unificación de 1937, solo serán focos con bastante autonomía que irían enlazándose paulatinamente y poco a poco con la Falange en el origen. En 1937, con el Decreto $\mathrm{n}^{0} 255$ 182/1937, la Falange Exterior adquiere el grado de Delegación Nacional, siendo uno de los apartados de la Junta Política - órgano director del nuevo partido único -. El primer Delegado Nacional será José del Castaño Cardona, nombrado el 14 de junio de 1937 por decreto de Franco y tomando posesión el 15 de agosto de ese mismo año. Del Castaño se encargará inicialmente de «incorporar al Estado Nacionalsindicalista a los españoles expatriados» ${ }^{13}$. Por otro lado, establecerá la organización de la Delegación Nacional del Servicio Exterior - de aquí en adelante DNSEF -. Para ello, inicia la redacción de un reglamento que regiría el organismo, ya que debía ser la delegación que controlara y fiscalizara a las falanges de cada país, aunque, en última instancia, su objetivo era llegar a controlar la colonia ${ }^{14}$ de españoles del país intentando reproducir y proyectar sobre los españoles residentes la estructura nacionalsindicalista. El 15 de diciembre de 1938 aparecía en la publicación falangista Nueva España de Guayaquil (Ecuador) el «Reglamento, normas y disposiciones sobre la Falange Exterior», ${ }^{15}$. El documento aparece firmado por el entonces Delegado Nacional, José del Castaño. Esto nos muestra que, desde que Del Castaño tomó posesión del cargo, se trabajó en la regulación de las Falanges Exteriores, culminando con la aprobación de dicho reglamento. Además de la publicación guayaquileña, y tal como indica González Calleja ${ }^{16}$, las publicaciones de Unidad en Lima y Avance en San Juan de Puerto Rico 
recogen el reglamento simplificado con el título: Cómo funcionan las falanges en el exterior. Es cierto que el Reglamento permanecerá sin ninguna modificación en toda la etapa que duró el Servicio Exterior, excepto el programa de reforma del servicio que, en 1940, redactó Fernando $\mathrm{M}^{\mathrm{a}}$ Castiella, pero que no llegó a ser aplicado ${ }^{17}$. Aun así, cabe destacar que se fueron emitiendo diferentes circulares a lo largo de sus años de vida para permitir la adaptación al contexto de cada momento.

7 Para llevar a cabo la labor falangista en el exterior, se crearon diferentes departamentos que debían adaptarse a la legalidad de cada país dónde se constituyese un núcleo. Esto suponía tener que adaptarse a cada contexto y circunstancias especiales, dotándose de gran flexibilidad. En muchos casos se optaba por la fórmula de 'organización apolítica', pero a pesar de dicha presentación, tal definición era falaz ya que entraba en contradicción «no solo con su carácter imperialista, sino también por sus estrechas relaciones con grupúsculos y organizaciones autóctonas de corte fascista o ultranacionalista ${ }^{18}$. Los departamentos generados se hicieron, en mayor parte, a imitación de los propios de la FET-JONS en la Península, como era la Sección Femenina o el Auxilio Social, este último creado en 1937 «sobre el esquema del WinterHilfe alemán $»^{19}$. Pero al mismo tiempo, dentro de la misma Falange peninsular se creó el Departamento de la Hermandad Exterior, que dirigía algunas de las actividades similares a las realizadas por el Auxilio Social de FET-JONS dentro de la península, lo que implicaba para la DNSEF la unificación y dirección de todas las actividades de caridad que realizasen las organizaciones afines al Movimiento dentro de las colonias de españoles. Estas acciones consistían en dar una ayuda benéfica y caritativa a los españoles expatriados que estaban en situaciones críticas, lo que permitía implementar una imagen más 'agradable' de lo que era la propia Falange. Aun así, tanto la Hermandad Exterior, como el Auxilio Social se solapaban en las actividades dirigidas fuera de la península.

8 En la Jefatura Nacional de la Sección Femenina se centralizó, inicialmente, el trabajo desempeñado por las Secciones Femeninas exteriores, donde Pilar Primo de Rivera jugaba el papel de «regidora central»" $»^{20}$, pero para 1938 ya contaba con una cabeza propia visible, bajo el mando de María Josefa Villamata, y de la Sección Femenina dependió la organización de los servicios de asesoramiento laboral, sanitarios o de derecho para los emigrantes españoles. Así, acabada la guerra en 1939, se pueden contar más de una veintena de Secciones Femeninas en el exterior, lo que hace pensar que existen también en estos sitios agrupaciones falangistas.

9 Las actividades de todos estos departamentos fueron diferentes, y buscaban incluir a los grupos de españoles expatriados dentro de la comunidad nacional, todo ello de acuerdo con el modelo de fascistización del Estado que se estaba impulsando. Oficinas de trabajo y colocación, albergues, dispensarios, centros de cultura y recreo, asesorías jurídicas, y una serie de servicios para los emigrantes españoles ${ }^{21}$, pero todo ello implicaba la organización y control de la propia vida privada y pública de estos españoles, ya que con todas estas actividades los ligaban al aparato del modelo fascista del estado, haciendo parte de él a todos los ciudadanos, peninsulares o de ultramar. Además, durante la Guerra Civil se llevaron a cabo actividades como «talleres para la confección de ropas destinadas a los combatientes $»^{22}$, y también recaudación de víveres, medicinas y dinero a través de diferentes actividades. Las 'madrinas de guerra' o la «acogida de niños huérfanos o combatientes heridos» ${ }^{23}$ acababan de conformar todas estas actividades. 
10 Todo este despliegue activista se basó en el propio reglamento, que en ningún caso fue modificado, a pesar del anteriormente citado intento de Castiella de 1940. Sin embargo, a lo largo de la vida del Servicio Exterior, se fueron emitiendo diferentes circulares desde la DNSEF para poder ayudar a adaptar la organización falangista a cada país y contexto. Con todo lo anterior, la división en departamentos de los diferentes campos del Servicio Exterior no dejaba de imitar la propia constitución del Nuevo Estado, con un proyecto de fascistización no solo del propio país a nivel interno, sino también de su fuerza exterior.

11 Otro de los trabajos de la DNSEF, sobre todo durante la Guerra Civil, fue la propaganda favorable a la Junta Técnica del Estado, y, a partir de 1938, cuando se cree el primer gobierno de Franco, al llamado Gobierno de Burgos. La actividad propagandística desde 1937 fue frenética, sobre todo en Latinoamérica, donde existían mayor número de grupos falangistas. Así, para el periodo comprendido entre agosto de 1937 y octubre de 1938, se llegaron a publicar casi un millón (sic) de artículos propagandísticos ${ }^{24}$, desde boletines informativos, revistas o cartas, hasta folletos varios; y no sólo en castellano, también en francés, inglés y alemán, aunque estos en menor medida. Esta labor propagandística no siempre fue desarrollada con normalidad, en muchos sitios se enfrentaban con la propaganda republicana, pero también los propios impedimentos de los gobiernos foráneos, sobre todo en el México de Cárdenas. La propaganda se centralizó a través del Departamento de Intercambio y Propaganda Exterior.

Toda esta propaganda se complementó con misiones culturales de distinta índole. Este modo de hacer llevaba impreso el sello falangista de la "vocación de imperio", que se resume en el discurso del falangista Antonio Aragón en Tetuán en 1937: «Que España tiene, efectivamente, por su historia y por su tradición, una voluntad de imperio, pero no una idea imperialista (...) $»^{25}$. Estas misiones culturales se realizaban a través de viajes desde España de jerarcas del régimen, una serie de intelectuales afines a Franco. Realizaban conferencias, seminarios, encuentros, exposiciones, etc. Toda una serie de actividades que complementaban la labor que ya desempeñaba el Departamento de Intercambio y Propaganda Exterior, que en 1938 editaba unas 17 revistas y periódicos en toda Latinoamérica ${ }^{26}$.

13 Tanto las secciones como la propaganda organizaban actividades para hacer imperar sobre los españoles emigrados un único modelo cultural, dirigido desde el nuevo partido único y el gobierno ilegítimo del general Francisco Franco. Esto llevó necesariamente a implementar una colaboración entre los cuadros falangistas del país y los representantes oficiosos del gobierno de Burgos. Sin embargo, a veces la diferencia entre afiliado/miliciano y diplomático no es tan nítida como se presupone. Aun así, el servicio contó con dirigentes y algunos jerarcas franquistas entre sus filas. En el estado actual de la investigación, pueden constatarse hasta una cincuentena de nombres que, en mayor o menor grado, se relacionaron con la DNSEF y, después de 1945, o bien acabaron en el cuerpo diplomático bien con cargos de importancia dentro del propio régimen.

14 La Delegación Nacional del Servicio Exterior contó, desde 1937, con seis Delegados Nacionales, y aparte de éstos existieron otras figuras como Secretarios Nacionales y otros subalternos, así como Jefes de Falange en los lugares donde se implantó, o Inspectores de Falange para diversas zonas, como era el caso del Inspector de Falange Exterior para los Balcanes e Italia ${ }^{27}$, por poner un ejemplo. 
15 Entre los Delegados Nacionales, el primero fue José del Castaño y Cardona, del cual ya se ha hablado con anterioridad, que impulsó el Reglamento de la DNSEF. Del Castaño era diplomático de carrera. Durante la Segunda República dirigió la Sección de Ultramar, y, al inicio de la Guerra Civil, se unió al bando sublevado, pasando con éxito el expediente que le abrió, a principios de 1937, la Comisión Depuradora de la Carrera Diplomática, de la cual, por cierto, acabaría siendo miembro; unos meses antes de la creación oficial de la DNSEF, ocupó el cargo de Secretario de Relaciones Exteriores en la Jefatura Técnica del Estado ${ }^{28}$. En agosto de 1937 fue nombrado Delegado Nacional del Servicio Exterior, cargo que ocuparía hasta mayo 1939, y jugó un papel clave en la canalización de las donaciones de las que se han hablado, así como de llevar a buen puerto en las colonias de españoles la unificación entre la Falange y el resto de grupos que quedaron al abrigo del partido único, FET-JONS ${ }^{29}$. Después de dejar el cargo, en noviembre de 1940 fue enviado a Filipinas como Cónsul General, al tiempo que también era nombrado jefe de Falange en Manila y para el resto de Filipinas ${ }^{30}$.

En esta etapa se le relaciona con el Incidente Laurel, propiciado por el entonces ministro de exteriores, el Conde de Jordana. De Jordana había felicitado al gobierno títere que los japoneses habían impuesto en el archipiélago, lo que había incomodado a los países Aliados. La implicación de del Castaño vendrá por su actitud colaboracionista con los japoneses en Filipinas después de que estos ocupasen las islas ${ }^{31}$. Del mismo modo, esta actitud le valdría ser detenido y deportado a España en 1945, cuando los Estados Unidos toman el archipiélago en el curso de la guerra. Después de esto sería destinado a Cuba como encargado de negocios, pero su reputación como Cónsul en Filipinas, así como algún incidente con el gobierno cubano -a lo que cabría sumar su pasado como Delegado Nacional del Servicio Exterior-, generaron problemas entre los gobiernos de Cuba y España, por lo que, finalmente, se le trasladó a otra legación latinoamericana. ${ }^{32}$. En los años siguientes, y hasta que se jubilara en 1965, pasó por diferentes embajadas con el cargo de embajador. Durante sus estancias en Manila y La Habana demostró en muchas ocasiones su incapacidad e incompetencia para la labor diplomática ${ }^{33}$; sin embargo, sus diversos nombramientos y ascensos, aunque fueran en embajadas poco importantes, hacen pensar que se le quiso premiar por su labor de antaño al frente de la DNSEF.

17 A del Castaño le sustituyó Rafael Sánchez Mazas en el mes de mayo de 1939. El trabajo de Sánchez Mazas al frente de la Delegación apenas dejó un rastro significativo; a pesar de ello, Sánchez Mazas hizo un buen aporte de ideas al servicio; pese a todo, acabada la guerra en abril de 1939, la organización exterior falangista entró en un breve declive, que no se corregiría con la gestión de Sánchez Mazas. Cabe destacar que de esta gestión nacen los Departamentos de Orientación Comercial, cuyo objetivo era expandir el comercio exterior a través de la DNSEF, y aquí podemos encontrar la base de la creación, a partir de 1941, de las JONS de la Marina Mercante ${ }^{34}$. También, Sánchez Mazas pondría las bases del quintacolumnismo que las falanges reavivadas a partir de la llegada de Serrano Suñer a Exteriores realizarían a favor del Eje en diversos países donde llegaron a implantarse núcleos fascistas españoles.

Se podría decir que el paso de Sánchez Mazas por el servicio fue poco más que un «interregno», ya que apenas estuvo cinco meses en el cargo, a pesar de algunas de las ideas que aportó. De la DNSEF saltó al gobierno de Franco como ministro sin cartera. También fue Consejero Nacional del Movimiento y procurador de las Cortes. En 1940 fue nombrado miembro numerario de la RAE (Real Academia Española de la Lengua), y 
en 1951 presidente del Patronato del Museo del Prado. Todo ello muestra que Sánchez Mazas puede ser el caso de excepción de miembro de la DNSEF con una carrera diplomática posterior, debido, probablemente, a su figura de «camisa vieja».

Tras Sánchez Mazas, en septiembre de 1939, fue designado Ricardo Giménez-Arnau Gran. Éste se unió al bando faccioso en la guerra, incorporándose a la Armada, y llegando a obtener el grado de Almirante de navío ${ }^{35}$. Ocupó el cargo de delegado de la DNSEF desde 1939 hasta 1941. Su hermano, José Antonio Giménez-Arnau Gran, fue designado por Serrano Suñer Secretario Nacional de Prensa y Propaganda en $1938^{36}$. Tras su cese como delegado de la DNSEF en 1942, Giménez-Arnau ingresó en la Escuela Diplomática $^{37}$, lo que luego le llevó a ocupar cargos en diferentes consulados y embajadas. Empezó como Cónsul General en Valparaíso (Chile), de ahí pasó a la legación española en Ankara (Turquía), accediendo más tarde al cargo de agregado de Economía Exterior de la representación en México. Todo ello en apenas 6 años. En 1951 recabó en la embajada española en Washington, yendo luego a la de Londres. En 1953 es enviado a Viena. Después de Viena pasó por Hamburgo en 1962 y luego por Rabat en 1963. En 1964, le llegaría su primer cargo como embajador, con destino en Santo Domingo (República Dominicana). En 1970, es destinado como embajador en Marruecos, donde finaliza su carrera diplomática. También fue delegado para organismos internacionales como el FMI, el Banco Mundial o la OIEA ${ }^{38}$.

La carrera de Giménez-Arnau parece ser otro ejemplo, como el de del Castaño, de recompensa por sus servicios políticos. Resultaría de interés analizar si el acceso de Giménez-Arnau al cuerpo diplomático fue, en parte, avalado por su servicio al frente de la DNSEF, ya fuera el acceso a la Escuela Diplomática, primero, o el nombramiento para algunos cargos diplomáticos de relevancia tras abandonar la misma.

21 A Giménez-Arnau le sustituyó, en agosto de 1941, Felipe Ximénez de Sandoval. A finales de 1940, Ramón Serrano Suñer había saltado de la cartera de Gobernación a la de Asuntos Exteriores, en el marco de un giro germanófilo y de una creciente fascistización del gobierno y del régimen franquistas. Desde esta nueva posición, Serrano daría un nuevo impulso a la DNSEF, y de ahí la recuperación a mediados de 1941 de un exdirigente del primer Servicio Exterior anterior a la unificación en 1937 como era Ximénez de Sandoval.

22 Ximénez de Sandoval se había afiliado en 1933 a Falange Española, año en el que también ingresa en el cuerpo diplomático. Había subido en el partido desde la Sección de Prensa y Propaganda en 1936, de la mano de José Manuel Aizpurúa y Azqueta ${ }^{39}$; su incorporación a dicha sección fue el resultado natural de sus en diversos diarios y revistas fascistas desde el momento mismo de su entrada en el partido. Durante la guerra civil combatió con los facciosos, enrolado en el Crucero Canarias.

23 Ximénez de Sandoval había dirigido temporalmente el primer Servicio Exterior, cuando Hedilla estaba a la cabeza de la Falange pre-unificada. Por ello, en 1941, Serrano Suñer lo recupera, y lo nombra jefe de su gabinete. Unos meses después vuelve a acceder a la dirección de la DNSEF, desempeñando el cargo hasta 1942, cuando es despedido de forma fulminante en el mes de marzo. Al parecer, todo vino motivado por un altercado con jóvenes monárquicos con motivo de acusaciones de homosexualidad sobre su persona $^{40}$. Esto también le valió la expulsión del partido, y su envío al extranjero.

24 Ximénez de Sandoval destacó también como escritor y articulista, y fue conocido sobre todo por su nada imparcial biografía de José Antonio Primo de Rivera ${ }^{41}$. Que Ximénez de Sandoval no acabase en la carrera diplomática parece ser que tiene mucho que ver con 
el incidente antes mencionado, lo que truncó cualquier posibilidad de ascenso político y diplomático en el seno del régimen, llevándolo a desempeñarse como escritor.

Fernando María Castiella y Maíz sucedió a Ximénez de Sandoval en el cargo de Delegado Nacional, y es, sin duda, uno de los nombres más interesantes de la lista de los delegados de la DNSEF, ya que «se trata de un personaje crucial para explicar la política exterior española en el periodo $1957-1969 »^{42}$. Es cierto que Castiella nunca llegó a ocupar formalmente el cargo. Nombrado en el mes de noviembre de 1942, en el mes de marzo del año siguiente fue sustituido ${ }^{43}$. Aun así, su implicación en el régimen tras 1939 no plantea la menor duda, ya que, entre otras cosas, participó en la redacción de una de sus «Leyes Fundamentales», concretamente el Fuero de los Españoles. Del mismo modo, acabó siendo director del Instituto de Estudios Políticos (IEP), fábrica de muchas de las políticas y de elaboración de discurso del régimen. Antes del inicio de la guerra había conseguido la cátedra de derecho internacional en la Universidad de La Laguna ${ }^{44}$, pero el estallido de la guerra le cogió en Madrid, y debido a su vínculo con los propagandistas, a parte de sus antecedentes con la incursión electoral en el Grupo Alfonsino Laurakbat en 1931, que le valió una breve estancia en prisión ${ }^{45}$, se vio obligado a permanecer escondido en casas particulares hasta 1937, y hasta marzo de 1939 refugiado en la embajada noruega. Entonces consiguió huir hasta Burgos, donde se afilió al recién creado partido único FET de las JONS. Superando el tribunal depurador, fue reestablecido en su cátedra, ya que había sido apartado por el gobierno republicano a inicios de la Guerra Civil. Tras su llegada a Burgos, se inició su ascenso meteórico en el aparato del Nuevo Estado siendo nombrado, primero, Juez Depurador en el Instituto de España, y luego miembro del Tribunal Permanente de Arbitraje Internacional de La Haya y consejero, en 1941, del recién creado Consejo de la Hispanidad ${ }^{46}$ del cual redactó el reglamento de funcionamiento.

Como ya se comentó anteriormente, en 1940 redactó un programa de reforma del Servicio Exterior, sin embargo, y a pesar de poder acceder al cargo de Delegado Nacional del Servicio Exterior dos años más tarde, el contexto no le permitió aplicar esa reforma basada en el modelo fascista que pretendía eliminar los viejos modos diplomáticos e inyectar personal joven en el cuerpo. En 1940 publicó junto a Areilza el libro Reivindicaciones de España, una oda imperialista a los "históricos" derechos españoles sobre ciertos territorios como Gibraltar o el Orán francés. Esta publicación, junto con los diversos textos que venía realizando desde la década de los treinta, demuestran cómo en la etapa que va hasta 1945, Castiella mantiene una posición filofascista bastante clara; y ello sin olvidar que en 1941 se enroló en la División Azul, de la cual regresó a los ocho meses galardonado con la Cruz de Hierro, que le fue entregada personalmente por Hitler ${ }^{47}$. Hasta 1948 su actividad se centró en el IEP y en la universidad, habiendo sido designado decano de la novísima Facultad de Ciencias Política y Económicas, creada en 1943.

En 1948, Alberto Martín-Artajo, ministro de exteriores desde 1945, lo nombra embajador en Perú, donde permanecerá hasta 1951, año en que fue nombrado embajador ante la Santa Sede. La intención inicial era que accediera al cargo de embajador en Londres, reforzando así el trabajo de Lequerica, embajador en Washington. Sin embargo, el gobierno británico rechazó su nombramiento. Poco después se le propuso la cartera de Educación, pero la rechazó, lo que llevó a ésta a Ruiz Jiménez, embajador ante el Vaticano, dejando así libre la vacante a la que, como ya se ha dicho, accedería Castiella. En 1957 será requerido para ocupar el Palacio de Santa 
Cruz, sede del Ministerio de Asuntos Exteriores, y desde ahí se convertirá en el artífice del gran cambio en la diplomacia española. Cumpliría así con su sueño de juventud, ser Ministro de Estado ${ }^{48}$.

A Castiella le sustituyó al frente de la DNSEF, en marzo de 1943, Antonio Riestra del Moral (1909-1984), que sería el último delegado de la DNSEF; la Delegación Nacional desapareció en octubre de 1945, al menos en la práctica, ya que pasó a depender de la Secretaría General del Movimiento y fue vaciada de contenido. Este trabajo fue asignado a Riestra del Moral, que se encargó durante su mandato de la desarticulación del servicio. Al mismo tiempo, algunas acciones, como el envío de una nota de felicitación a los Estados Unidos tras la entrada de sus tropas en Manila (Filipinas), fueron un intento de limar asperezas y descargar al Servicio Exterior de la imagen fascista y de quintacolumnismo que había adquirido durante la contienda mundial.

Riestra del Moral provenía de familia nobiliaria y ostentó el título del marquesado de Riestra, como tercer marqués. Descendiente de militares y políticos, tomó parte en la Guerra Civil en el bando franquista, militando a su vez en FE de las JONS. Pertenecía al Cuerpo Jurídico Militar ${ }^{49}$, y su cargo como delegado de la DNSEF le dio acceso al Consejo Nacional, siendo miembro de los siguientes consejos por designación directa de Franco, a pesar de no tener asignada ninguna Delegación Nacional. Con la creación de las Cortes Orgánicas, ocupó el cargo de procurador de las mismas hasta 1971, en su condición de miembro del Consejo Nacional del Movimiento.

De todo lo explicado hasta ahora, se desprende que al menos la mitad de los Delegados Nacionales del Servicio Exterior acabaron en el cuerpo diplomático del estado franquista, en el que ostentaron cargos importantes, como los de embajador o cónsul. De la otra mitad de delegados, cabe destacar el caso de Ximénez de Sandoval, a quien se puede incluir en el saco de los "no premiados", pues si bien el incidente mencionado más arriba truncó su carrera, probablemente, si este no hubiese tenido lugar, hubiera acabado en cargos diplomáticos importantes. Sobre los otros dos delegados, Sánchez Mazas y Riestra del Moral, cabe indicar que el primero ya era una figura prominente del partido único antes de ocupar la Delegación, lo que explica buena parte de su trayectoria posterior; mientras que Riestra del Moral acabó teniendo un papel importante en la política interior, continuando en el Cuerpo Jurídico Militar y como procurador de las Cortes.

31 Pero aparte de los delegados nacionales, la Falange tuvo que cubrir otros cargos de la organización exterior, como el de Secretario Nacional del Servicio Exterior, que fue ocupado por 4 personas diferentes entre 1938 y 1945.

Joaquín Rodríguez de Gortázar y Pastor ocupó el cargo entre 1938 y 1939, y posteriormente fue Inspector General de Falange Exterior (sin zona concreta). Fue autor de Los mandatos internacionales en la política colonial, publicado en 1928, un estudio acerca de las cuestiones coloniales en relación con la política exterior y las relaciones internacionales. También fue autor de artículos como «La cuestión romana ${ }^{50}$, algunos de ellos publicados en medios de corte fascista. Rodríguez de Gortázar acabará siendo, en los años 60, embajador en Bolivia ${ }^{51}$.

Rodríguez de Gortázar fue sustituido en 1939, como Secretario Nacional, por José Jiménez Rosado, que se mantuvo en el cargo hasta $1941^{52}$. Jiménez Rosado era licenciado en derecho, y un año después de abandonar la secretaría se convirtió en miembro del Cuerpo de Técnicos Comerciales del Estado. En 1941, poco después de abandonar la secretaría, y hasta 1943, fue designado directamente por Serrano Suñer 
como agregado comercial de la Embajada de Bucarest, al servicio del Conde de CasaRojas $^{53}$. José Jiménez Rosado era hijo de un primer matrimonio de la Condesa de CasaRojas, Victoria Rosado y Sánchez Pastor, con Manuel Jiménez Souvirón, que los había abandonado cuando Jiménez Rosado contaba 5 años ${ }^{54}$.

Genaro Riestra Díaz sustituía a Jiménez Rosado al frente de la secretaría de la delegación, y ostentó el cargo hasta $1943^{55}$. Español de origen mexicano ${ }^{56}$, en 1929 había regresado al país centroamericano como empleado de comercio ${ }^{57}$. Antes de acceder al secretariado de la DNSEF, fue nombrado cónsul general en La Habana, y jefe de Falange en Cuba en 1940, pero en 1941, con la ilegalización de Falange por parte del gobierno de ese país, Riestra es detenido y deportado a España. Tras cesar como Secretario Nacional de la DNSEF, fue nombrado Gobernador de Pontevedra, y desde 1944 de Vizcaya, siendo también Jefe Provincial del Movimiento en la provincia vasca. Desde 1943, y hasta su muerte, ocupó el cargo de Consejero Nacional ${ }^{58}$.

Sergio Cifuentes González-Posada fue Secretario Nacional de Falange Exterior desde agosto de $1943^{59}$, y hasta la desaparición de la DNSEF, convirtiéndose en el último Secretario Nacional antes de la absorción de la organización por parte de la Secretaría General del Movimiento. En 1955 es nombrado vocal de la Junta Nacional de la Vieja Guardia $^{60}$.

Pero aparte de los Secretarios Nacionales, encontramos algunos nombres relevantes, como el de Eduardo Aunós Pérez, José Félix de Lequerica y Erquiza, o Agustín de Foxá. Lequerica y Aunós coincidieron en Francia; el primero ocupó el cargo de embajador en ese país desde 1939 hasta 1944, cuando es requerido para sustituir al conde de Jordana al frente del Ministerio de Asuntos Exteriores. Su actividad en Francia ya ha sido bastante bien estudiada por María Jesús Cava Mesa ${ }^{61}$; hay que destacar que, en sus años, primero desde París, y con la ocupación nazi de Francia en 1940, desde Vichy, no cesó en su labor de perseguir a los exiliados republicanos en Francia; por otro lado, fue un colaborador del gobierno del mariscal Pétain, con lo que consiguió tejer una red de contactos con diferentes miembros del gobierno francés tanto antes como después de la ocupación. Forjó una estrecha relación con Pierre Laval y Pétain, y obtuvo la condecoración de la Gran Cruz de Águila Alemana por parte de los nazis y la Gran Cruz Legión de Honor por parte de Pétain por su intervención en el armisticio franco-alemán de 194062; probablemente, todo ello le supuso problemas para ocupar embajadas más adelante, con posterioridad a 1945, pero también quizás su corta estancia en el Palacio de Santa Cruz -menor de un año- tuviera que ver con el cercano final de la guerra y el miedo de Franco bien a una intervención, bien a que los acuerdos comerciales con británicos y estadounidenses, así como la 'integridad colonial' del Sahara, Guinea o el Ifni, se vieran comprometidos.

Cabe recordar también que Lequerica llevó la voz cantante en la negociación con la Gestapo para que Lluís Companys, president de la Generalitat de Catalunya, fuera conducido a España, donde sería fusilado.

Uno de los apoyos falangistas de Lequerica en Francia durante 1939-1944 fue Eduardo Aunós, inicialmente como Jefe de Falange en Francia, y posteriormente también como Inspector General de Falange para Francia, Bélgica y Suiza. Aunós había entrado en la política de la mano de Francesc Cambó, a través de la Lliga Regionalista de Catalunya y en 1918 se convirtió en diputado, repitiendo en 1920 después de la suspensión jurídica del Congreso de los Diputados. Durante los años 20 abandonó su catalanismo político, y con la Dictadura de Primo de Rivera se convierte en secretario del Ministerio de 
Trabajo, Comercio e Industria, pasando a ser en 1924 el titular de la cartera ministerial hasta 1930. En 1931, con la proclamación de la Segunda República, se suma a los exiliados monárquicos y se acerca a Acción Española. Con el estallido de la Guerra Civil se afilia, en 1937, a Falange Española de las JONS. Es entonces cuando se convierte en jefe de Falange en Francia, y también será miembro de la Junta Política de FET-JONS y Consejero Nacional. Durante su estancia en el país galo, se le encomendaron diversas misiones diplomáticas y comerciales por Italia ${ }^{63}$, al tiempo que participaba, como jurista, en la elaboración del documento que declaraba ilegítimo al gobierno de la República. En 1939 fue nombrado embajador en Bélgica, y en 1942 en Argentina ${ }^{64}$. Su aventura diplomática finalizará en 1943, cuando es requerido para ocupar el Ministerio de Justicia. Tras cesar como ministro en 1945, ocupa el cargo de procurador de las Cortes y el de miembro del Tribunal de Cuentas, cargos que ostentará hasta su muerte ${ }^{65}$. Finalmente, Agustín de Foxá, conde de Foxá, en 1936 ocupó el cargo de secretario de la embajada española en Bucarest, bajo las órdenes del embajador en Rumanía, Pedro Prat y Soutzo, y también junto a Luis Beneyto Martí, vicecónsul honorario. Con el estallido de la guerra en julio, los tres se sumarán al bando faccioso. Prat y Soutzo quedará como representante oficioso del bando sublevado, Beneyto como Jefe Provincial de FET-JONS en Rumanía y Agustín de Foxá como Inspector General de Falange Exterior para los Balcanes e Italia ${ }^{66}$. Sobre la actuación de Foxá desde Bucarest en esta época es interesante tener en cuenta Misión en Bucarest y otras narraciones, libro que publicó en 1961 y donde relata su vivencia allí. Durante la Segunda Guerra Mundial fue el embajador español en Finlandia, luego trabajó con Areilza en la embajada de Buenos Aires entre 1947 y 1950, y después es destinado a la embajada en La Habana bajo las órdenes de Juan Pablo de Lojendio e Irure.

En el periodo posterior a 1945, el franquismo sobrevivió en dos frentes: internamente, donde siguió imponiendo la mano dura y el inmovilismo, manteniendo los trazos originales del régimen; exteriormente, jugándose la supervivencia ante los vencedores en la Segunda Guerra Mundial.

Los especialistas apuntan habitualmente a que la causa fundamental de la supervivencia exterior radica en la posición que Estados Unidos empieza a adoptar respecto a la Unión Soviética muy poco después de acabada la contienda mundial. Una política de contención de la que nacen los decisivos convenios con Franco en septiembre de 1953, que daría paso a la creación de las bases de Rota, Morón, Torrejón y Zaragoza. Parecía que el estigma del régimen desaparecía. El viraje emprendido en 1945 respecto al bloque de los aliados parecía que daba sus frutos a mediados de los 50 . Si bien el pacto con Estados Unidos era muestra de ello, en 1953 también se firmaba el Concordato con la Santa Sede, y dos años más tarde España ya pertenecía al club de las Naciones Unidas ${ }^{67}$, y ya no quedaba ni rastro de las denuncias planteadas por Polonia en 1946 ni de las resoluciones contra el régimen de Franco que se aprueban en la ONU ese mismo año ${ }^{68}$. Pero hubo otros elementos, en los que ahora se pone interés.

En primer lugar, Franco se alineó, en el contexto internacional posterior a 1945, con la hipótesis, muy común en aquel momento, de que el mundo se encaminaba hacia una Tercera Guerra Mundial, y España, la primera vencedora del bolchevismo en los campos de batalla, como solía decir falazmente la propaganda del régimen, tendría un papel básico y central como retaguardia estratégica segura y 'consejera' de las potencias occidentales. En aquel momento España era el refugio de fascistas y nazis que escapaban de Europa con destino a América, donde sus conocimientos sobre la Unión 
Soviética serían aprovechados en breve ante la posibilidad de un nuevo conflicto bélico que no parecía entonces tan fantasioso. Es conocido el comentario de Franco a Eisenhower (ambos militares) a raíz de su encuentro en 1959: «Ya tardaron ustedes mucho en venir». Así, en caso de una nueva contienda generalizada, el régimen no necesitaría cambiar demasiado su cara externa, y simplemente habría de seguir los pasos del Portugal de Salazar, pro-aliado durante la Segunda Guerra Mundial.

Por otro lado, tras la Segunda Guerra Mundial, la historiografía tiende a exponer más los cambios que tiene lugar que las cosas que continúan. Caso de Latinoamérica, donde continuaron existiendo regímenes autoritarios y populistas de diferentes signos, como la Argentina de Perón, el Brasil de Getulio Vargas, el Ecuador de Velasco Ibarra o la Costa Rica de Calderón. En el mundo mediterráneo y el Próximo Oriente, los procesos de descolonización traían consigo la aparición de nuevos estados independientes que se constituían en torno a regímenes autoritarios y a políticos que habían sido colaboradores del Eje, o con idearios que daban la sensación de recordar al fascismo y al nacionalsindicalismo, como el partido Baaz ${ }^{69}$. En estas dos partes del globo, el régimen de Franco se movía con relativa soltura, y podía, llegado el caso, actuar como interlocutor e intermediario, pues no debe olvidarse que Franco se había formado como un general colonialista, había luchado en África y conocía el mundo musulmán, de lo cual hacía teatral ostentación cotidiana con su Guardia Mora.

En este contexto se puede decir que Madrid estaba bien informada de lo que sucedía tanto en Latinoamérica como en el ámbito mediterráneo después de 1945, escenarios convulsos y, por ello, teatros potenciales de una posible guerra generalizada.

Sobre estas bases, el estudio del periodo 1945-1959 resulta ciertamente sugerente en vistas a entender cómo se produce la transformación de la política exterior franquista como avanzada del cambio interior del régimen producido durante la década de $1960 \mathrm{y}$ 1970. Al final de este periodo, marcado por una supuesta autarquía y aislacionismo, se consolidó la posición de España como parte del bloque occidental; pero dentro de este proceso y de ese aislacionismo no tan aislante y de una autarquía no tan autárquica como se acostumbra decir, cabría observar cómo se produce la mutación de la paradiplomacia falangista, aportando los rasgos de una diplomacia di combattimento cuya experiencia sobre el terreno resultaba útil para entender qué estaba cambiando, o no, a través de los antiguos contactos forjados por los falangistas en los años de la guerra civil y la guerra mundial.

Hasta ahora las investigaciones sobre la labor paradiplomática falangista, y en gran parte también sobre la propiamente diplomática del primer franquismo, se han reducido a su papel propagandístico del Nuevo Estado. Este hecho es constatable por el uso de las fuentes primarias utilizadas para su estudio, mayoritariamente revistas de época editadas por el propio Servicio Exterior. Ahora bien, esa paradiplomacia también estuvo orientada a obtener información de todo tipo, incluyendo la comercial. Si el régimen de Franco propició un giro de orientación y estilo político sin romper el statu quo entre 1945 y 1959, ¿hasta qué punto el antiguo personal de Falange Exterior fue reciclado en diplomacia de carrera en esos años? ¿Cómo contribuyeron con sus contactos y conocimientos de los años críticos (1937-1945) a entender las incertidumbres de los nuevos y viejos escenarios? ¿Cómo evolucionaron los planteamientos ideológicos de los integrantes del antiguo servicio reconvertidos en la imagen de una dictadura, a la fuerza, más moderada que la de la inmediata postguerra? 
47 Para dar respuesta a esas preguntas, una reconstrucción lo más fehacientemente posible de las biografías de estos hombres al servicio de la Falange podría ayudar, en muchos casos, a entender los entresijos y la evolución de un servicio que, como ya se ha dicho, no ha sido tan estudiado como otras secciones del que fuese partido único del régimen dictatorial del general Franco. Además, se puede encontrar, como en los ejemplos mostrados, una conexión entre el trabajo en el servicio falangista y los posteriores trabajos al servicio de la diplomacia franquista después de 1945, como los casos de José del Castaño, Ricardo Giménez-Arnau o Joaquín Rodríguez de Gortázar. El estudio en profundidad de muchas de estas biografías podría aclarar algunas dudas sobre el despliegue de la diplomacia franquista después de 1945, cuando muchas incertidumbres planeaban sobre el futuro del mundo.

Es urgente afrontar el estudio de la transformación, funciones y protagonismo de los antiguos miembros de Falange Exterior en la deriva de la política exterior del régimen de Franco entre 1945 y 1959. Los conocimientos y acciones de ese personal político pudieron ayudar a guiar una política exterior que permitió a una dictadura fascista superar unos años complicados y decisivos para su supervivencia. Todo lo cual ayudaría también a ampliar la visión sobre cómo se articuló ese nuevo despliegue diplomático.

Pero, además, se debe apuntar hacia otros caminos, como los procesos de descolonización, donde cabría observar y conocer en mayor profundidad cuál fue el papel de España, y cómo conjugaría eso con el discurso imperialista y la propia pugna del régimen por recuperar el espacio, tanto real como imaginario, de los que antaño fueron territorios coloniales españoles. Y esta recuperación debería entenderse tanto en términos de «territorio ocupado» como de imperialismo cultural, algo que ya antes de 1945 había iniciado el famoso Consejo de la Hispanidad enfocando su actuación, sobre todo, hacia Latinoamérica, donde la España franquista pudo encontrar simpatías, como, por ejemplo, por parte de la Argentina de Perón. Evita Perón fue una de las pocas dirigentes y representantes políticas latinoamericanas que viajaron a España en aquellos años; en su caso, concretamente, en la primavera de 1947. Tras su derrocamiento en 1955, el comandante Perón acabaría fijando su residencia en el exilio en España a partir de 1960; allí se casó con su tercera y última esposa, «Isabelita» Perón, la cual reside, actualmente, en la villa de Madrid.

50 También se debe apuntar a otros elementos que completen el análisis más general, como el proceso, primero de condena, y luego de aparente aceptación, del régimen español en la ONU, sobre el cual ya se ha hablado anteriormente. Este camino empieza con las resoluciones de 1946 y acaba con la de 1955, mediante la cual España es aceptada como miembro de pleno derecho. Pero más interesante es el hecho de que el Consejo de Seguridad solo realizase, en el periodo 1946-1955, tres resoluciones ${ }^{70}$ concretas sobre la situación española, y que, por el contrario, la situación griega tuvo en el mismo periodo el doble de resoluciones. Este proceso -para el caso español, de menos de una década-, ¿debe entenderse en el marco de los acuerdos implícitos que van estableciendo Estados Unidos y la Unión Soviética sobre control y ampliación de sus respectivas 'Esferas de Influencia'? Y ¿qué papel juegan en todo este proceso los países latinoamericanos?

51 Existe, pues, una línea de trabajo a explorar sobre la diplomacia franquista que se plantea como hipótesis que el régimen de Franco, en el periodo 1945-1959, sobrevivió internacionalmente gracias al trabajo realizado en diversos frentes: en primer lugar, mediante el reciclado del viejo personal de Falange Exterior; y en segundo, mediante la 
explotación no solo de la "vía norteamericana», sino también de otros espacios aparentemente secundarios, como el arábigo o el latinoamericano.

\section{NOTAS}

1. Herbert R. Southworth, Antifalange: estudio crítico de "Falange en la guerra de España: la Unificación y Hedilla" de Maximiano García Venero, París, Ruedo Ibérico, 1967.

2. Eduardo González Calleja, «El Servicio Exterior de Falange y la política exterior del primer franquismo: Consideraciones previas para su investigación», Hispania, LIV/1, no 186, 1994, p. 279-307; Eduardo González Calleja, «Fascismo para la exportación: la delegación nacional del servicio exterior de falange española», Revista Horizontes Sociológicos, nº 3, 2014, p. 121-139 y Eduardo González Calleja, «La propaganda exterior de la FET y de las JONS (1936-1945)», en Antonio C. Moreno Cantano (coord.), El ocaso de la verdad: Propaganda y prensa exterior en la España franquista (1936-1945), Trea, Gijón, 2011, p. 157-190.

3. Florentino Rodao, Franco y el Imperio Japonés, Barcelona, Plaza y Janés, 2002; Id., «José del Castaño y Cardona, más falangista que diplomático», en Antonio C. Moreno Cantano (coord.), Cruzados de Franco: Propaganda y diplomacia en tiempos de guerra (1936-1945), Gijón, Trea, 2013, p. 179-210.

4. Francisco Veiga Rodríguez, «Falange Exterior: Les limitacions de la diplomàcia blava», L'Avenç (dossier), nº 109, 1987 p. 9; Id., «La guerra de las embajadas. La Falange Exterior española en Rumanía y Oriente Medio, 1936-1944», Revue Roumaine d'Histoire, tomo XXIX, 3-4, 1990 p. 321-335; Id., «La guerra de les ambaixades: La Falange Exterior a Romania i l'Orient Mitjà, 1936-1944», L'Avenç (Dossier), noํ 109, 1987 p. 10-18; Id., «Diplomacia en camisa azul. La Falange Exterior española en Rumanía y Oriente Medio, 1936-1944», en Javier Tusell (dir.), Rosa Pardo Sanz (coord.) et alii, La Política exterior de España en el siglo XX, Madrid, UNED, 1997, p. 201-215.

5. Antonio C. Moreno Cantano (coord.), Cruzados de Franco: Propaganda y diplomacia en tiempos de guerra (1936-1945), Gijón, Trea, 2013; Id. (coord.), «Guerra de propagandas en Rumanía durante la contienda bélica española (1936-1939)», en Historia Actual Online, núm. 20, 2009, p. 129-141.

6. Eduardo"González Calleja, op. cit., 1994, p. 281.

7. Ibidem.

8. «Decreto no 255» en BOE 182/1937 del 20 de abril, Burgos, 20/04/1937 (https://www.boe.es/datos/ pdfs/BOE//1937/182/A01033-01034.pdf)

9. Eduardo González Calleja, op. cit., 2014, p. 122.

10. El uso del concepto colonia en el texto, se refiere a los grupos de migrantes españoles que residían, por la razón que fuese, fuera de la Península Ibérica antes, durante e inmediatamente después de la Guerra Civil. No confundir con el concepto colonia referente a territorio de ultramar ocupado, conquistado o dirigido por una nación, p. e. Ifni, Orán o Río de Oro.

11. Maximiliano García Venero, Falange en la guerra de España: la unificación y Hedilla, París, Ruedo Ibérico, 1967, p. 314. 
12. Eduardo González Calleja, op. cit., 2011, p. 157.

13. Eduardo González Calleja, op. cit., 2014, p. 122.

14. Vid. nota 10.

15. «Reglamento, normas y disposiciones sobre la Falange Exterior», en Nueva España (Guayaquil, Ecuador), 15 de diciembre de 1938, p. 5-7.

16. Eduardo González Calleja, op. cit., 2014 p. 125, nota 12.

17. Rosa Pardo Sanz, «Fernando María Castiella: pasión política y vocación diplomática», en Historia Contemporánea, nº 15, Bilbao, 1996, p. 230.

18. Ibid.

19. Ibid. p. 124.

20. Eduardo González Calleja, op. cit., 2014, p. 123.

21. Ibid. p. 124.

22. Ibid.

23. Ibid.

24. Eduardo González Calleja, op. cit., 1994 p. 285-286

25. Citado en Eloy Martín Corrales, «La bandera del Marroc i els 'camarades moros': la participación marroquina a les files falangistes», L’Avenç (Dossier), nº 109, 1987, p. 21-22. Nota 25: «Presente (órgano de la Falange en Tánger), 13 de abril de 1937.»

26. Eduardo González Calleja, op. cit., 2014, p. 125.

27. Francisco Veiga Rodríguez, op. cit., 1987, p. 10; Antonio C. Moreno Cantano, op. cit., 2009, p. 130.

28. Florentino Rodao, op. cit., 2013, p. 181.

29. Ibid. p. 182.

30. Florentino Rodao, op. cit., 2002, p. 214; Id., op. cit., 2013, p. 190-191.

31. Florentino Rodao, op. cit., 2002, p. 298

32. Florentino Rodao, op. cit., 2013, p. 208

33. Ibid.

34. Eduardo González Calleja,, op. cit., 2014, p. 126

35. «Fallecimiento de Don Ricardo Giménez Arnau», ABC, 21 de junio de 1972, p. 36 (http://hemeroteca.abc.es/nav/Navigate.exe/hemeroteca/madrid/abc/ 1972/06/21/036.html)

36. Lorenzo Delgado Gómez-Escalonilla, Imperio de papel: acción cultural y política exterior durante el primer franquismo, Madrid, CSIC, 1992, p. 77.

37. Ibid.

38. Ibid.

39. Maximiliano García Venero, op. cit., 1967, p. 264.

40. Eduardo González Calleja, op. cit., 1994, p. 295.

41. Felipe Ximénez de Sandoval, Biografía apasionada de José Antonio, Barcelona, Ed. Juventud, 1941.

42. Rosa Pardo Sanz, «Fernando $M$ Castiella: una larga travesía hacia el liberalismo», en Juan Avilés Farré (coord.), Historia, política y cultura (Homenaje a Javier Tusell), Madrid, UNED, 2009, p. 393.
43. Ibid., p. 404.
44. Ibid., p. 399.
45. Ibid., p. 396
46. Ibid., p. 400.
47. Ibid., p. 403. 
48. Así lo relató Begoña Castiella, hija del exministro, en una entrevista mantenida con el autor en Madrid el 17 de enero de 2017.

49. Eduardo González Calleja, op. cit., 1994, p. 295.

50. Joaquín Rodríguez de Gortázar y Pastor, «La cuestión romana», en La Gaceta Literaria, año III, no 52, 1929, p. 5. No creo que pueda decirse que la revista era de corte fascista en 1929 .

51. «Instrumento de ratificación del Convenio de doble nacionalidad entre el Estado español y la República de Bolivia», en BOE 90/1964, 14 de abril, p. 4655.

52. Eduardo González Calleja, op. cit., 2014, p. 133.

53. José A. Lisbona Martín, Más allá del deber: la respuesta humanitaria del Servicio Exterior frente al Holocausto, MAEC, Madrid, 2015, p. 144

54. Ibid.

55. Eduardo González Calleja, op. cit., 2014, p. 133.

56. Ficha personal de Genaro Riestra Díaz, Registro Nacional de Extranjeros en México, Secretaría de Gobernación de México, AGA-RIEM/219/093, ES.28005.AGA (copia digital).

57. Ibid.

58. Ficha de Genaro Riestra Díaz, Congreso de los Diputados, Histórico de diputados 1810-1977: (http://www.congreso.es/portal/page/portal/Congreso/Congreso/SDocum/ArchCon/

SDHistoDipu/SDBuscHisDip?_piref73_1340033_73_1340032_1340032.next_page=/wc/ servidorCGI\&CMD=VERLST\&BASE=DIPH\&FMT=DIPHXLSS.fmt\&DOCS=1-100\&DOCORDER=FIFO\&OPDEF=Y\&QUERY=\%2895560.NDIP. \%29)

59. Eduardo González Calleja, op. cit., 2014, p. 133. Nota al pie no 43.

60. «Nueva Junta de la Vieja Guardia», $A B C, 31$ de marzo de 1955, p. 34.

61. María Jesús Cava Mesa, «José Félix de Lequerica, embajador en Francia (1939-1944): El gesto retórico», en Antonio C. Moreno Cantano (coord.), Propagandistas y diplomáticos al servicio de Franco (1936-1945), Gijón, Trea, 2012, p. 81-120.

62. Ibid., p. 113.

63. Sergio Fernández Riquelme, «Política, Autoridad y Trabajo. Eduardo Aunós y el Estado corporativo en España», en La razón histórica. Revista hispanoamericana de Historia de las Ideas, nำ10, 2010, p. 30.

64. Ibid.

65. Ibid., p. 31.

66. Francisco Veiga Rodríguez, op. cit., 1987, p. 10; Antonio C. Moreno Cantano, op. cit., 2012, p. 130.

67. Resolución 995(X)/1955 de la ONU: Admisión de Nuevos miembros en las Naciones Unidas, 555ª sesión plenaria, 14 de diciembre de 1955 (copia digital).

68. Resolución 32(I)/1946 de la ONU: Relaciones entre los miembros de las Naciones Unidas y España, 26 sesión plenaria, 9 de febrero de 1946 (copia digital); y Resolución 39(I)/1946 de la ONU: Relaciones de los Miembros de las Naciones Unidas con España, 59ª sesión plenaria, 12 de diciembre de 1946 (copia digital). Popularmente conocidas como The Spanish Question.

69. Johannes Houwinck Ten Cate, «Collaboration with the Third Reich: The Wider Historical Debate and the Role of Haj Amin al-Husseini, Mufti of Jerusalem», en Jewish Political Studies Review, 26, 3-4, 2014, p. 91-113; Jeffrey Herf, « La propagande nazie destinée au monde arabe pendant la Seconde Guerre Mondiale et la Shoah; ses conséquences ", Revue d'Histoire de la Shoah, 205 (2), 2016, p. 107-126; y Pierre-André Taguieff, «Fanatiques antijuifs sur la voie du jihad. Dans le sillage de Haj Amin al Husseini et de Johann von Leers», en Revue d'Histoire de la Shoah, 205 (2), 2016, p. 475-510.

70. Resolución 4/1946 del 29 de abril, 7/1946 del 26 de junio y 10/1946 del 4 de noviembre, del Consejo de Seguridad de la ONU (copias digitales). 


\section{RESÚMENES}

El Servicio Exterior de Falange ha sido una de las secciones de Falange Española menos estudiada por los investigadores. Desde la obra de H. R. Southworth en 1967, dónde por primera vez se habla de la Falange Exterior, a las aportaciones más recientes se han cubierto muchos aspectos de esa organización, como un todo o en sus actividades en países concretos, así como en su despliegue de propaganda política. Existe, pues, una línea de trabajo a explorar sobre la diplomacia franquista que se plantea como hipótesis que el régimen de Franco, en el periodo 1945-1959, sobrevivió internacionalmente gracias al trabajo realizado en diversos frentes: en primer lugar, mediante el reciclado del viejo personal de Falange Exterior; y en segundo, mediante la explotación no solo de la 'vía norteamericana', sino también de otros espacios aparentemente secundarios, como el arábigo o el latinoamericano.

Le Service extérieur de la Phalange a été l'une des sections de la Phalange espagnole les moins étudiées par les chercheurs. Depuis l'ouvrage de H. R. Southworth en 1967, où l'on parle pour la première fois de l'action extérieure de la Phalange, les contributions les plus récentes ont couvert de nombreux aspects de cette organisation, comme un tout ou dans ses activités dans des pays spécifiques, ainsi que dans son déploiement de propagande politique.

Il existe donc une ligne de travail à explorer sur la diplomatie franquiste qui pose comme hypothèse que le régime de Franco, au cours de la période 1945-1959, a survécu internationalement grâce au travail accompli sur divers fronts : premièrement, par le recyclage de l'ancien personnel de la Phalange Extérieure; et deuxièmement, grâce à l'exploitation non seulement de la «voie nord-américaine», mais également d'autres espaces apparemment secondaires comme dans le monde arabe ou latino-américain.

The Falange Foreign Service has been one of the sections of the Spanish Phalange less studied by researchers. From the work of H. R. Southworth in 1967, where the Foreign Phalanx is first spoken of, to the most recent contributions many aspects of that organization have been covered, as a whole or in its activities in specific countries, as well as in its display of political propaganda. There is, therefore, a line of work to be explored on Franco's diplomacy that hypothesizes that the Franco regime, in the period 1945-1959, survived internationally thanks to the work done on various fronts: firstly, by recycling the old staff of Falange Exterior; and secondly, by exploiting not only the American way, but also other seemingly secondary spaces, such as the Arabic or the Latin American way.

\section{ÍNDICE}

Keywords: Phalange, Foreign policy, propaganda, Spain, 20th century

Mots-clés: Phalange, Politique étrangère, propagande, Espagne, XXe siècle

Palabras claves: Falange, política exterior, propaganda, diplomacia

\section{AUTOR}

\section{IVÁN GARNELO MORÁN}

Universitat Autònoma de Barcelona 